\title{
Hydrogen Sensors Using Nitride-Based Semiconductor Diodes: The Role of Metal/Semiconductor Interfaces
}

\section{Yoshihiro Irokawa}

National Institute for Materials Science, 1-1 Namiki, Tsukuba 305-0044, Japan;

E-Mail: irokawa.yoshihiro@nims.go.jp; Tel.: +81-29-860-4549; Fax: +81-29-860-4914

Received: 21 December 2010 / Accepted: 6 January 2011 / Published: 11 January 2011

\begin{abstract}
In this paper, I review my recent results in investigating hydrogen sensors using nitride-based semiconductor diodes, focusing on the interaction mechanism of hydrogen with the devices. Firstly, effects of interfacial modification in the devices on hydrogen detection sensitivity are discussed. Surface defects of GaN under Schottky electrodes do not play a critical role in hydrogen sensing characteristics. However, dielectric layers inserted in metal/semiconductor interfaces are found to cause dramatic changes in hydrogen sensing performance, implying that chemical selectivity to hydrogen could be realized. The capacitance-voltage $(C-V)$ characteristics reveal that the work function change in the Schottky metal is not responsible mechanism for hydrogen sensitivity. The interface between the metal and the semiconductor plays a critical role in the interaction of hydrogen with semiconductor devises. Secondly, low-frequency $C-V$ characterization is employed to investigate the interaction mechanism of hydrogen with diodes. As a result, it is suggested that the formation of a metal/semiconductor interfacial polarization could be attributed to hydrogen-related dipoles. In addition, using low-frequency $C-V$ characterization leads to clear detection of $100 \mathrm{ppm}$ hydrogen even at room temperature where it is hard to detect hydrogen by using conventional current-voltage $(I-V)$ characterization, suggesting that low-frequency $C-V$ method would be effective in detecting very low hydrogen concentrations.
\end{abstract}

Keywords: GaN; AlGaN; Schottky barrier diodes; hydrogen sensors 


\section{Introduction}

Recently, hydrogen has attracted considerable attention as a clean energy source instead of petroleum. Hydrogen also has many important applications such as its use in the processes of many industries that include the chemical, petroleum, food and semiconductor sectors. A hydrogen leak should be avoided because hydrogen when mixed with air in the ratio larger than $\sim 4$ vol.\% is explosive. For this reason, it has become very important to develop highly sensitive hydrogen detectors with a large variety of specifications to prevent accidents due to hydrogen leakage. Such detectors should allow continuous monitoring of the concentration of gases in the environment in a quantitative and selective way. Therefore, hydrogen sensors would form an integral part of any such systems incorporating hydrogen.

Solid-state hydrogen sensors under flow-through conditions are mainly classified into the following categories: pyroelectric, piezoelectric, fiber optic, electrochemical, and semiconductor sensors [1]. Among them, semiconductor device hydrogen detectors exhibit the highest sensitivity at elevated temperatures [1]. In many applications such as fuel cells and chemical process monitoring in industries, gas sensing with high sensitivity and low detection limit in harsh environments is required. Wide-band-gap compound semiconductor materials including $\mathrm{SiC}$ and $\mathrm{GaN}$ have been candidates for high-temperature gas sensing applications [2-5]. Due to the large band-gap of $\mathrm{GaN}$ and $\mathrm{SiC}$, and the associated chemical stability and mechanical robustness, these semiconductors can be used for many harsh applications, satisfying a considerable interest in developing hydrogen gas sensors capable of operation in harsh environmental conditions such as high-temperature and chemically corrosive ambients. These include gas sensing operations during chemical reactor processing, onboard fire alarms on aircraft and space vehicles, as well as detection of fuel leaks in automobiles and aircraft, to name but a few. A unique advantage of a $\mathrm{GaN}$ gas sensor is that it can be integrated with GaN-based optical devices or high-power, high-temparature electronic devices on the same chip. Another advantage of nitride-based semiconductor devices is a utilization of AlGaN/GaN heterostructure. In an $\mathrm{AlGaN} / \mathrm{GaN}$ heterostructure, the polarization-induced two dimensional electron gas (2DEG) concentration at the $\mathrm{AlGaN} / \mathrm{GaN}$ interface is extremely sensitive to surface states. Any potential changes on the surface by adsorption of gas or liquid polar molecules, or pressure change would affect the surface potential and modulate the 2DEG density. Therefore, devices on AlGaN/GaN heterostructures have great potential for chemical gas sensing in harsh environments. Furthermore, the fabrication of nitride-based sensors on Si contributes to lower production cost. On the other hand, technical drawbacks for SiC devices are that the processing, particularly of SiC FETs (field-effect transistors), is inherently complicated, requiring high-temperature implantation and very high-temperature post-implantation annealing steps, leading to higher cost. Therefore, nitride-based semiconductor sensors are investigated in this report.

Hydrogen is reported to be able to alter the effective charge at the metal/semiconductor interface or metal/dielectric interface, resulting in changes in barrier height [6,7]. This effect is utilized in semiconductor based gas sensors fabricated on various semiconductor materials such as Si [8], $\mathrm{SiC}[4,5]$, and $\mathrm{GaN}[2,3]$. The interaction of hydrogen with semiconductor devices has long been studied, and intensive research led to a model which attributes the reaction mechanism of the devices to hydrogen to the formation of a hydrogen-induced dipole layer at the metal/dielectric/semiconductor 
interface [8-12]. Lundström and co-workers investigated the influence of hydrogen on $\mathrm{Pd}$ or $\mathrm{Pt}-\mathrm{SiO}_{2}-\mathrm{Si}$ structure using various methods, including internal photoemission, polarization currents, $C$ - $V$ measurements, and Kelvin probe. As a result, they concluded the interaction mechanism as follows: molecular hydrogen adsorbs on $\mathrm{Pd}$ or Pt surface and dissociates. Hydrogen atoms diffuse through Pd or Pt and adsorb at the metal-oxide interface, forming a dipole layer. The dipole layer is responsible for the work function change, for example, showing up as a voltage shift in the $C$ - $V$ characteristics of the device. Despite the existence of a considerable quantity of experimental data, however, there are still some debates as to the origin of the hydrogen sensitivity. For example, a work function decrease in the Schottky metals, such as $\mathrm{Pd}$ and $\mathrm{Pt}$, on exposure to hydrogen is reported to be the origin of the changes in the characteristics of devices $[13,14]$. The role of the interface state density in the interaction of hydrogen with semiconductor devices is also discussed in previous reports [13]. Even now, the interaction mechanism of hydrogen with semiconductor devices still remains to be mysterious. In order to fabricate hydrogen sensors with higher performances, for example, those with selectivity for hydrogen, the interaction mechanism of hydrogen with semiconductor devices should be elucidated. Especially, the metal/semiconductor interfaces play a key role in the interaction mechanism in the devices. Here, I investigate the interaction mechanism of hydrogen with the nitride-based semiconductor diodes, focusing on the metal/semiconductor interfaces.

\section{Experimental}

Metal organic chemical vapor deposition (MOCVD) grown undoped GaN, Si-doped GaN (n-type $5 \times 10^{17} \mathrm{~cm}^{-3}$ ) epilayers, and AlGaN/GaN heterostructures on (0001) $\mathrm{Al}_{2} \mathrm{O}_{3}$ substrates were used for this study, respectively. For Pt-GaN Schottky barrier diodes (SBDs), Ti(20 nm)/Al(100 nm)/ $\mathrm{Pt}(40 \mathrm{~nm}) / \mathrm{Au}(100 \mathrm{~nm})$ multi-layers were formed on either $2 \mu \mathrm{m}$ undoped GaN films or $2 \mu \mathrm{m}$ Si-doped $\mathrm{GaN}$ films grown on undoped $1 \mu \mathrm{m} \mathrm{GaN}$ layers by lift off of electron beam evaporation as ohmic contacts. The contacts were subsequently annealed at $750{ }^{\circ} \mathrm{C}$ for $30 \mathrm{~s}$ under a flowing $\mathrm{N}_{2}$ ambient in a rapid thermal annealing (RTA) system. Then, Schottky contacts were formed by lift-off of electron beam deposited $\operatorname{Pt}(25 \mathrm{~nm}$ ). For metal-insulator-semiconductor (MIS) Pt-GaN diodes, either a $10 \mathrm{~nm}$ $\mathrm{SiO}_{2}$ or a $10 \mathrm{~nm} \mathrm{Si}_{\mathrm{x}} \mathrm{N}_{\mathrm{y}}$ dielectric layer was produced by radio-frequency sputtering at room temperature and lift-off before the Schottky contact formation. For Pt-AlGaN/GaN Schottky barrier diodes, the sample consisted of a buffer layer, an unintentionally doped GaN layer ( $3 \mu \mathrm{m}$ thick), and an unintentionally doped AlGaN layer $(20 \mathrm{~nm})$ with an $\mathrm{Al}$ mole fraction of $24 \%$. The AlGaN/GaN hetero-structure showed typical 2DEG properties with the sheet carrier concentration of $7.9 \times 10^{12} \mathrm{~cm}^{-2}$ and the mobility of $1,237 \mathrm{~cm}^{2} / \mathrm{Vs}$ as determined by room-temperature Hall-effect measurements. After growth, planar SBDs were fabricated as follows. First, Ti/Al/Pt/Au metals were sequentially deposited and then sintered at $850{ }^{\circ} \mathrm{C}$ for $30 \mathrm{~s}$ to create ohmic contacts. Finally, $25 \mathrm{~nm}$ thick Pt films were formed as Schottky contacts. For all the fabricated devices, the diameter of circular Schottky contacts was $300 \mu \mathrm{m}$, and the distance between the ohmic contact and the Schottky metal was $20 \mu \mathrm{m}$.

Hydrogen interaction with the devices was investigated using a stainless-steel reaction chamber with tungsten probes under a flowing ambient $(100 \mathrm{~mL} / \mathrm{min})$ of either $\mathrm{N}_{2}$ or $\mathrm{H}_{2}$ in $\mathrm{N}_{2}$ at a total pressure of $10.0 \mathrm{kPa}$ at room temperature. Here, either $1 \%$ or $100 \mathrm{ppm}_{2}$ in $\mathrm{N}_{2}$ gas was employed. The $C$ - $V$ and conductance-voltage $(G-V)$ characteristics were acquired using parallel circuit mode. 


\section{Results and Discussion}

\subsection{Effects of Interfacial Modification in the Devices on Hydrogen Detection Sensitivity}

For GaN Schottky diode-type hydrogen sensors, it was reported that an oxidic intermediate layer between the catalytic Schottky contact and the GaN surface is the origin of the hydrogen sensitivity of $\mathrm{Pd}-\mathrm{GaN}$ Schottky diodes, implying that the metal /semiconductor interfacial modification would lead to significant change in the interaction of hydrogen with devices [15]. Several authors have reported the critical role of the dielectric layer between the Schottky metal and the GaN surface in hydrogen sensitivity of devices [16-22]. In this report, firstly, hydrogen sensing characteristics of Pt-GaN Schottky diodes fabricated on intentionally defect-introduced GaN surfaces are investigated. Secondly, influence of dielectric layers, including $\mathrm{SiO}_{2}, \mathrm{Si}_{\mathrm{x}} \mathrm{N}_{\mathrm{y}}$ and $\mathrm{AlGaN}$ layers, between the metal and semiconductor interface on hydrogen detection was studied. Figure 1 shows the $I-V$ characteristics for a Pt-(Si-doped) GaN Schottky diode in a $\mathrm{N}_{2}$ ambient and the response to the exposure to $1 \% \mathrm{H}_{2}$ in $\mathrm{N}_{2}$ at room temperature.

The diode exhibits a good rectifying behavior in both ambients. The $I-V$ characteristics consist of the exponential region in the low-current region and the resistance-limited region in the high-current region. On the basis of the thermionic emission model for $V>3 k T / q$, the $I-V$ characteristics of Schottky diodes are described using:

$$
I_{F}=S A^{* *} T^{2} \exp \left(-\frac{q \Phi_{B}}{k T}\right)\left\{\exp \left(\frac{q V}{n k T}\right)-1\right\}
$$

where $I_{F}$ is the forward current, $S$ is the diode area, $A^{* *}$ is Richardson's constant for n-GaN $\left(24 \mathrm{Acm}^{-2} \mathrm{~K}^{-2}\right.$ ), $T$ is the absolute temperature, $k$ is Boltzmann's constant, $q$ is the electron charge, and $\Phi_{B}$ is the Schottky barrier height [23]. The ideality factor $n$ and Schottky barrier height $\Phi_{B}$ are extracted from Equation (1). Table 1 shows a summary of the extracted $n$ and $\Phi_{B}$ in both $\mathrm{N}_{2}$ and $1 \% \mathrm{H}_{2}$ in $\mathrm{N}_{2}$ from the $I-V$ characteristics shown in Figure 1.

Figure 1. $I-V$ characteristics for a $\mathrm{Pt}-\left(\mathrm{Si}\right.$-doped) GaN Schottky diode in a $\mathrm{N}_{2}$ ambient and the response to the exposure to $1 \% \mathrm{H}_{2}$ in $\mathrm{N}_{2}$ at room temperature. Reproduced with permission from reference [17]. Copyright The Japan Society of Applied Physics.

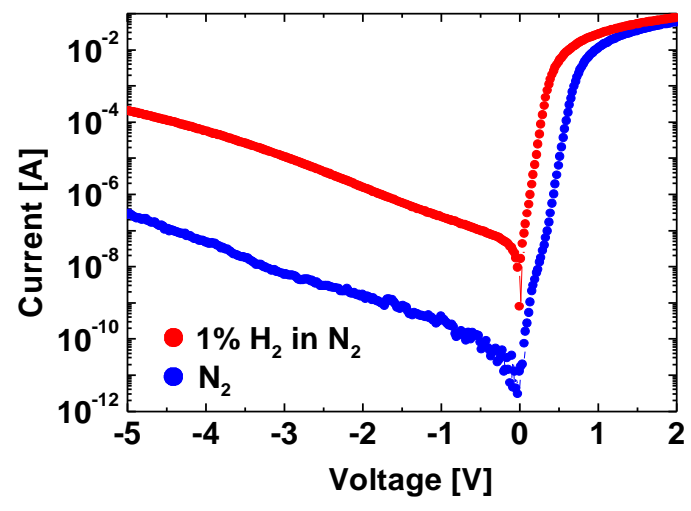


Table 1. Extracted $n$ and $\Phi_{B}$ in both $\mathrm{N}_{2}$ and $1 \% \mathrm{H}_{2}$ in $\mathrm{N}_{2}$ from the $I-V$ characteristics shown in Figure 1. Reproduced with permission from Reference [17]. Copyright The Japan Society of Applied Physics.

\begin{tabular}{lcc}
\hline & $\mathbf{N}_{\mathbf{2}}$ & $\mathbf{1 \%} \mathbf{H}_{\mathbf{2}}$ \\
\hline Ideality factor, $\mathrm{n}$ & 1.30 & 1.22 \\
Schottky barrier height $(\mathrm{eV})$ & 0.838 & 0.662 \\
\hline
\end{tabular}

The obtained $n$ and $\Phi_{B}$ in $\mathrm{N}_{2}$ are consistent with those previously reported [24]. Upon exposure of the device to $1 \% \mathrm{H}_{2}$ in $\mathrm{N}_{2}$ at room temperature, $n$ and $\Phi_{B}$ were found to be 1.22 and $0.662 \mathrm{eV}$, respectively. The reduction in the Schottky barrier height may be explained by the formation of a hydrogen-induced dipole layer between the metal and the semiconductor, which leads to the change in interfacial potential, as reported previously [6,7].

Next, hydrogen sensing characteristics of $\mathrm{Pt}-\mathrm{GaN}$ Schottky diodes fabricated on as-grown and annealed GaN surfaces are studied in order to investigate the correlation between the surface defects of $\mathrm{GaN}$ and hydrogen sensing performance. The GaN samples were annealed before contact formation in the RTA system. Figure 2 shows the sensitivity of Pt-(Si-doped) $\mathrm{GaN}$ Schottky diodes for $1 \% \mathrm{H}_{2}$ in $\mathrm{N}_{2}$ at room temperature as a function of the annealing temperature of the GaN surfaces. Here, the sensitivity is defined as a shift of voltage upon exposure to $1 \% \mathrm{H}_{2}$ in $\mathrm{N}_{2}$ at a current of $0.1 \mathrm{~mA}$. The error bars represent the range of the measured values.

As shown in Figure 2, the averaged value of the sensitivity of devices fabricated on as-grown surfaces, $900{ }^{\circ} \mathrm{C}$ and $1,000{ }^{\circ} \mathrm{C}$ annealed surfaces were $0.34,0.35$ and $0.34 \mathrm{eV}$, respectively. Significant differences of the sensitivity among the devices are not observed in Figure 2. In order to investigate the effects of carrier concentration of the films on hydrogen detection characteristics, undoped GaN films were employed. Figure 3 shows the sensitivity of $\mathrm{Pt}$-(undoped) GaN Schottky diodes for $1 \% \mathrm{H}_{2}$ in $\mathrm{N}_{2}$ at room temperature as a function of the annealing temperature of the $\mathrm{GaN}$ surfaces.

Figure 2. The sensitivity of $\mathrm{Pt}-\left(\mathrm{Si}\right.$-doped) GaN Shottky diodes for $1 \% \mathrm{H}_{2}$ in $\mathrm{N}_{2}$ at room temperature as a function of the annealing temperature of the $\mathrm{GaN}$ surfaces. The sensitivity is defined as a shift of voltage upon exposure to $1 \% \mathrm{H}_{2}$ in $\mathrm{N}_{2}$ at room temperature at a current of $0.1 \mathrm{~mA}$.

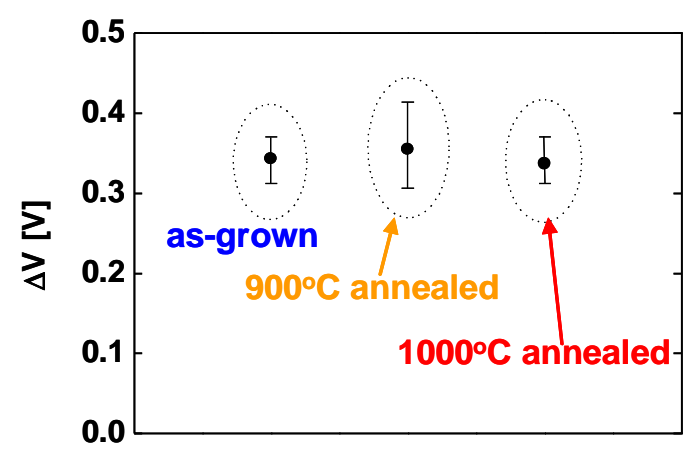


Figure 3. The sensitivity of $\mathrm{Pt}$-(undoped) $\mathrm{GaN}$ Shottky diodes for $1 \% \mathrm{H}_{2}$ in $\mathrm{N}_{2}$ at room temperature as a function of the annealing temperature of the $\mathrm{GaN}$ surfaces. The sensitivity is defined as a shift of voltage upon exposure to $1 \% \mathrm{H}_{2}$ in $\mathrm{N}_{2}$ at room temperature at a current of $0.1 \mathrm{nA}$. The inset shows the room temperature photoluminescence spectra of as-grown and $900{ }^{\circ} \mathrm{C}$ annealed $\mathrm{GaN}$ surfaces.

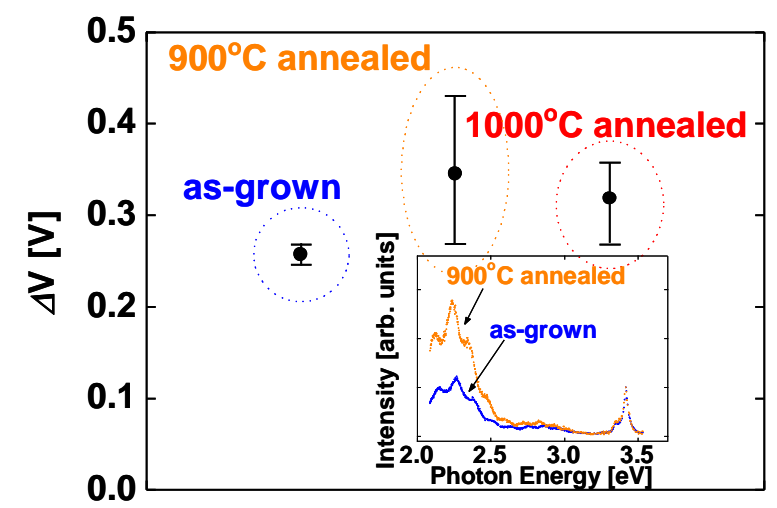

Here, the sensitivity is defined as a shift of voltage upon exposure to $1 \% \mathrm{H}_{2}$ in $\mathrm{N}_{2}$ at a current of $0.1 \mathrm{nA}$. The error bars represent the range of the measured values. Although the devices fabricated on annealed surfaces displayed a slightly increased sensitivity, taking the error bars of the sensitivity into consideration, significant differences of the sensitivity among the devices are not observed, once again. On the other hand, the inset of Figure 3 shows the room temperature photoluminescence spectra of as-grown and $900{ }^{\circ} \mathrm{C}$ annealed $\mathrm{GaN}$ surfaces. The spectra have near-bandedge emission around $3.4 \mathrm{eV}$. The broad deep level emission around $2.2 \mathrm{eV}$ is modulated by the Fabry-Perot interference fringes. As shown in the inset of Figure 3,900 ${ }^{\circ} \mathrm{C}$ annealed $\mathrm{GaN}$ sample shows stronger deep level emission around $2.2 \mathrm{eV}$ than as-grown sample does. This deep level emission is generally attributed to point defects and antisites, suggesting that high temperature annealing created these defects in the sample surface [25]. Though the PL spectra reveal the clear difference of the surface defects between as-grown and annealed surfaces as shown in the inset of Figure 3, the devices fabricated on annealed surfaces show the similar in hydrogen detection sensitivity to those on as-grown surfaces as shown in Figures 2 and 3. These results suggest that the surface defects of $\mathrm{GaN}$ do not play a critical role in hydrogen sensing characteristics of Pt-GaN Schottky diodes.

In order to investigate the influence of dielectric layers, including $\mathrm{SiO}_{2}, \mathrm{Si}_{\mathrm{x}} \mathrm{N}_{\mathrm{y}}$ and $\mathrm{AlGaN}$ layers, between the metal and semiconductor interface, on hydrogen detection sensitivity, hydrogen response of $\mathrm{Pt}-\mathrm{GaN}$ diodes with dielectric layers was studied. Figure 4 shows the schematic cross sections of the MIS Pt-GaN diodes with both $10 \mathrm{~nm} \mathrm{SiO}_{2}$ and $10 \mathrm{~nm} \mathrm{Si}_{x} \mathrm{~N}_{\mathrm{y}}$ dielectrics, respectively.

Figures 5(a,b) show the $I-V$ characteristics of MIS Pt-GaN diodes with both $10 \mathrm{~nm} \mathrm{SiO}_{2}$ and $10 \mathrm{~nm}$ $\mathrm{Si}_{\mathrm{x}} \mathrm{N}_{\mathrm{y}}$ dielectrics in $\mathrm{N}_{2}$ and response to exposure to $1 \% \mathrm{H}_{2}$ in $\mathrm{N}_{2}$ at room temperature, respectively. As shown in Figure 5(a), hydrogen exposure of a MIS Pt-GaN diode with a $\mathrm{SiO}_{2}$ dielectric causes marked changes in $I-V$ characteristics as compared with that of the conventional Schottky diode, as shown in Figure 1, demonstrating that the MIS devices with a $\mathrm{SiO}_{2}$ dielectric have a higher sensitivity to hydrogen than the conventional Schottky devices. Table 2 shows the sensitivities of the conventional 
$\mathrm{Pt}-\mathrm{GaN}$ Schottky diode and MIS Pt-GaN diodes in $1 \% \mathrm{H}_{2}$ in $\mathrm{N}_{2}$ extracted from Figures 1 and 5. Here, the sensitivities are defined as shifts in voltage upon exposure to $1 \% \mathrm{H}_{2}$ in $\mathrm{N}_{2}$ at a current of $0.1 \mathrm{~mA}$.

Figure 4. Schematic cross section of MIS Pt-GaN diodes with both $10 \mathrm{~nm} \mathrm{SiO}_{2}$ (a) and $10 \mathrm{~nm} \mathrm{Si} \mathrm{N}_{\mathrm{y}}$ dielectrics (b). Reproduced with permission from Reference [17]. Copyright The Japan Society of Applied Physics.

(a)

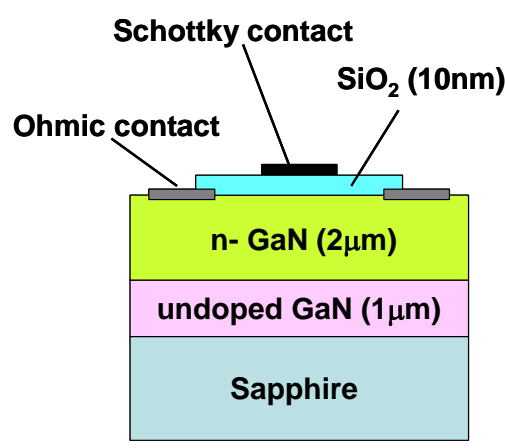

(b)

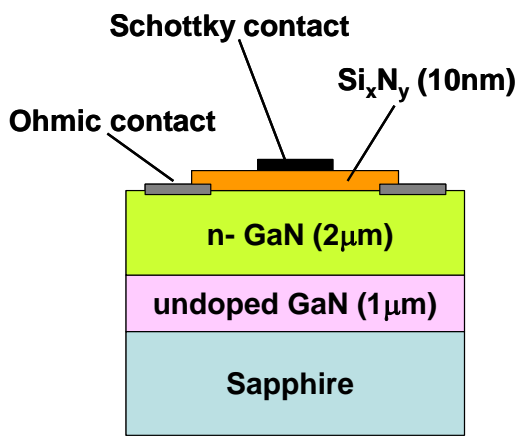

Figure 5. $I-V$ characteristics of MIS Pt-GaN diodes with both $10 \mathrm{~nm} \mathrm{SiO}_{2}$ (a) and $10 \mathrm{~nm}$ $\mathrm{Si}_{\mathrm{x}} \mathrm{N}_{\mathrm{y}}$ dielectrics (b) in $\mathrm{N}_{2}$ and response to exposure to $1 \% \mathrm{H}_{2}$ in $\mathrm{N}_{2}$ at room temperature. Reproduced with permission from Reference [17]. Copyright The Japan Society of Applied Physics.

(a)

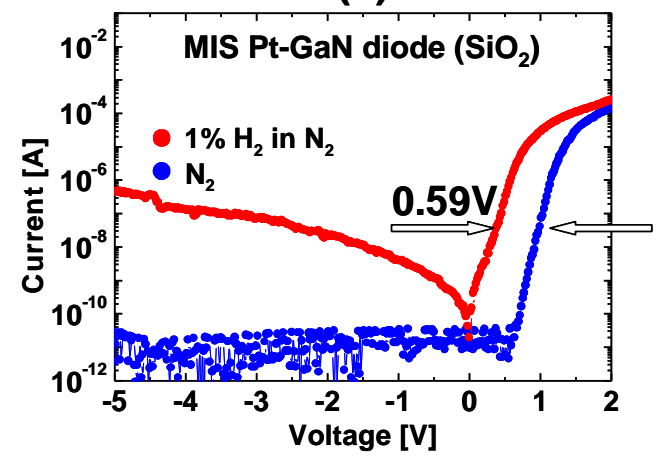

(b)

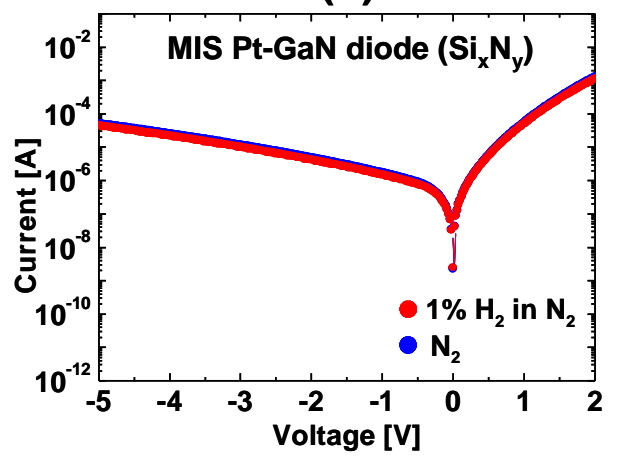

As shown in Table 2, the MIS Pt-GaN diode with a $10 \mathrm{~nm} \mathrm{SiO}_{2}$ dielectric shows a marked improvement in hydrogen detection sensitivity, which is twice higher than that of the conventional Pt-GaN Schottky diode. Upon changing the hydrogen-containing ambient into $\mathrm{N}_{2}$, the $I-V$ characteristics of the MIS Pt-GaN diode are found to revert to the initial values, although it takes a long time, that is, more than three hours at room temperature, just like the conventional Pt-GaN Schottky diode. In sharp contrast, a MIS Pt-GaN diode with a $10 \mathrm{~nm} \mathrm{Si}_{\mathrm{x}} \mathrm{N}_{\mathrm{y}}$ dielectric does not show any hydrogen response, as shown in Figure 5(b). Therefore, the hydrogen detection sensitivity of the device is found to be $0.00 \mathrm{~V}$, as shown in Table 2. More detailed electrical properties of these MIS $\mathrm{Pt}-\mathrm{GaN}$ diodes upon exposure to hydrogen are discussed in Section 3.2. 
Table 2. Sensitivities of conventional Pt-GaN Schottky and MIS Pt-GaN diodes in $1 \% \mathrm{H}_{2}$ in $\mathrm{N}_{2}$ extracted from Figures 1 and 5. Here, the sensitivities are defined as shifts in voltage upon exposure to $1 \% \mathrm{H}_{2}$ in $\mathrm{N}_{2}$ at a current of $0.1 \mu \mathrm{A}$. Reproduced with permission from Reference [17]. Copyright The Japan Society of Applied Physics.

\begin{tabular}{lc}
\hline & Sensitivity $(\mathbf{V})$ \\
\hline Schottky diode & 0.30 \\
MIS diode $\left(\mathrm{SiO}_{2}\right)$ & 0.59 \\
MIS diode $\left(\mathrm{Si}_{\mathrm{x}} \mathrm{N}_{\mathrm{y}}\right)$ & 0.00 \\
\hline
\end{tabular}

Hydrogen sensing characteristics of $\mathrm{Pt}-\mathrm{AlGaN} / \mathrm{GaN}$ diodes are generally reported like those of $\mathrm{Pt}-\mathrm{GaN}$ diodes. In Pt-AlGaN/GaN diodes, the $\mathrm{AlGaN} / \mathrm{GaN}$ hetero-interface structurally plays a major role in carrier transportation in an SBD. Moreover, in an AlGaN/GaN hetero-structure, the polarization-induced 2DEG concentration at the $\mathrm{AlGaN} / \mathrm{GaN}$ interface is extremely sensitive to surface states. Any potential changes on the surface by adsorption of gas or liquid polar molecules, or pressure change would affect the surface potential and modulate the 2DEG density, leading to application in excellent sensors. Since the AlGaN layer is undoped and considered to be an insulator, the $\mathrm{AlGaN} / \mathrm{GaN}$ structure would be regarded as one of MIS structures. Previously, only a few studies revealed the investigation of hydrogen detection sensitivity of $\mathrm{Pt}-\mathrm{GaN}$ and $\mathrm{Pt}-\mathrm{AlGaN} / \mathrm{GaN}$ Schottky diodes [26], and little is known about the comparative performances. In this report, hydrogen detection sensitivity of $\mathrm{Pt}-\mathrm{GaN}$ and $\mathrm{Pt}-\mathrm{AlGaN} / \mathrm{GaN}$ Schottky diodes is compared, and the results are shown in Figure 6.

Figure 6. $I-V$ characteristics of $\mathrm{Pt}-\mathrm{GaN}$ diode (a) and $\mathrm{Pt}-\mathrm{AlGaN} / \mathrm{GaN}$ diode (b) in $\mathrm{N}_{2}$ and response to exposure to $1 \% \mathrm{H}_{2}$ in $\mathrm{N}_{2}$ at room temperature.
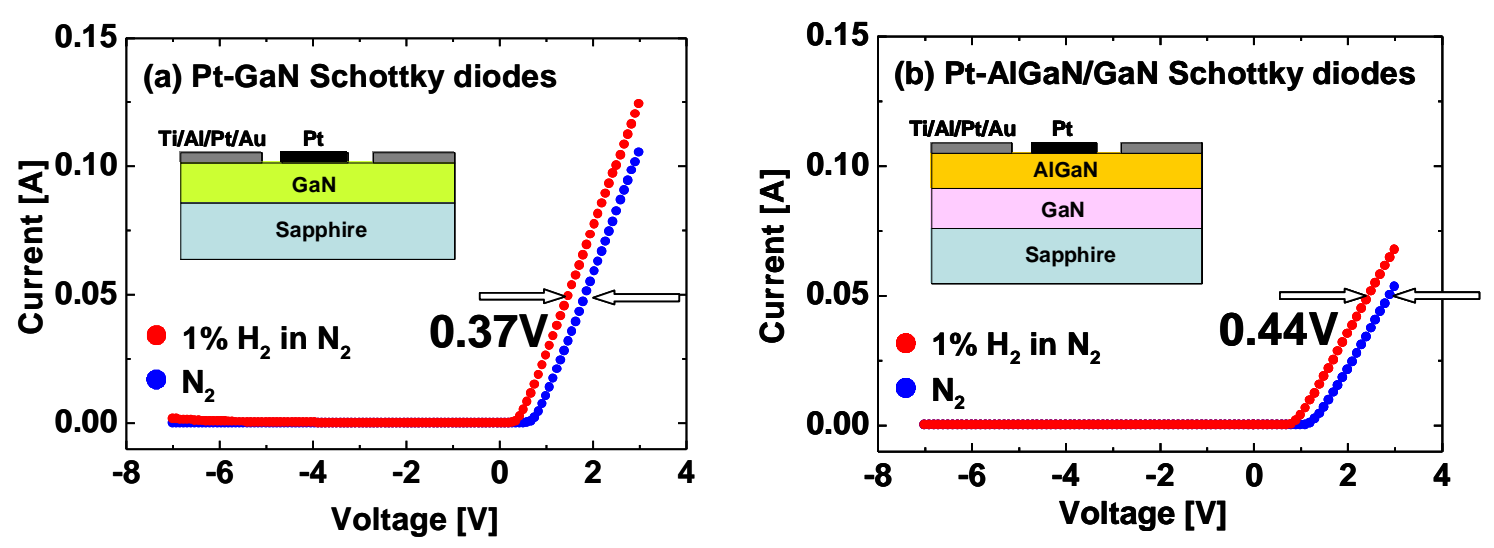

As shown in Figure 6, the sensitivities of the $\mathrm{Pt}-\mathrm{GaN}$ and $\mathrm{Pt}-\mathrm{AlGaN} / \mathrm{GaN}$ diodes are $0.37 \mathrm{~V}$ and $0.44 \mathrm{~V}$, respectively. Here, the sensitivities are defined as shifts in voltage upon exposure to $1 \% \mathrm{H}_{2}$ in $\mathrm{N}_{2}$ at a current of $0.05 \mathrm{~A}$. The Pt-AlGaN/GaN diode shows slightly higher sensitivity as compared with that of the $\mathrm{Pt}-\mathrm{GaN}$ device, consistent with the previous report [26]. Note that the $\mathrm{Pt}-\mathrm{GaN}$ diode show relatively higher leakage current in $\mathrm{H}_{2}$ ambient, as shown in Figure 6(a). In sharp contrast, $\mathrm{Pt}-\mathrm{AlGaN} / \mathrm{GaN}$ diode shows no leakage current in both ambients. Therefore, $\mathrm{Pt}-\mathrm{AlGaN} / \mathrm{GaN}$ devices 
would be suitable for application to highly-sensitive hydrogen sensors operated at high temperature. The detailed hydrogen sensing mechanism of Pt-AlGaN diodes are discussed in Section 3.3.

\subsection{Hydrogen-Induced Change in the Electrical Properties of Metal-Insulator-Semiconductor}

\section{Pt-GaN Diodes}

In the previous section, I compared the hydrogen response of MIS Pt-GaN diodes with both $10 \mathrm{~nm}$ $\mathrm{SiO}_{2}$ and $10 \mathrm{~nm} \mathrm{Si}_{\mathrm{x}} \mathrm{N}_{\mathrm{y}}$ dielectrics. As a result, MIS Pt-GaN diodes with a $\mathrm{SiO}_{2}$ dielectric showed a marked improvement in hydrogen detection sensitivity. In sharp contrast, MIS Pt-GaN diodes with a $\mathrm{Si}_{\mathrm{x}} \mathrm{N}_{\mathrm{y}}$ dielectric did not show any hydrogen response. Since the changes in the $I-V$ characteristics of devices are totally different for the two dielectric layers, detailed investigation for these phenomena would lead to the elucidation of the interaction mechanism of hydrogen with semiconductor devices. Here, $I-V$ and $C$ - $V$ characteristics are performed for MIS Pt-GaN diodes with both $\mathrm{SiO}_{2}$ and $\mathrm{Si}_{\mathrm{x}} \mathrm{N}_{\mathrm{y}}$ dielectrics, and the changes in the electrical properties are discussed.

The conduction mechanism for MIS $\mathrm{Pt}-\mathrm{GaN}$ diodes with both $\mathrm{SiO}_{2}$ and $\mathrm{Si}_{\mathrm{x}} \mathrm{N}_{\mathrm{y}}$ dielectrics is investigated as follows. In the oxide field range of $0.3-0.9 \mathrm{MV} / \mathrm{cm}$, for MIS Pt-GaN diodes with a $\mathrm{SiO}_{2}$ dielectric, the measured $I-V$ data in a $\mathrm{N}_{2}$ ambient were fitted using the Fowler-Nordheim (FN) tunneling model, as shown in Figure 7(a).

The FN model is given by:

$$
\begin{aligned}
& J=A E^{2} \exp \left(-\frac{B}{E}\right) \\
& A=\frac{q^{3} m}{8 \pi h m_{\text {dielec }} \Phi_{B}} \\
& B=\frac{8 \pi \sqrt{2 m_{\text {dielec }}}\left(q \Phi_{B}\right)^{3 / 2}}{3 q h}
\end{aligned}
$$

where $m_{\text {dielec }}$ is the effective electron mass in the dielectric, $m$ is the free electron mass, $q$ is the magnitude of electron charge, $\Phi_{B}$ is the barrier height, and $E$ is the dielectric electric field [27]. Here, the value of the effective mass used was equal to $m_{\text {dielec }}=0.5 m$ [28]. Since the plot of $\log \left(J / E^{2}\right)$ versus $1 / E$ is linear, as shown in Figure 7(a), the oxide conduction is FN conduction. The barrier height extracted from the FN plot as shown in Figure 7(a) is $2.9 \mathrm{eV}$, and this value is found to be consistent with the previously reported values for the $\mathrm{SiO}_{2} / \mathrm{GaN}$ interface $[28,29]$.

On the other hand, for MIS Pt-GaN diodes with a $\mathrm{SiO}_{2}$ dielectric, the measured $I-V$ data in a $\mathrm{H}_{2}$ ambient were fitted using the Pool-Frenkel emission model, as shown in Figure 7(b). The Pool-Frenkel emission model is given by:

$$
J \propto E \exp \left(-\frac{q\left(\phi_{B}-\sqrt{q E / \pi \varepsilon}\right)}{k T}\right)
$$

where $E$ is the dielectric electric field, $\varepsilon$ is the dielectric permittivity, $\phi_{B}$ is the trap level below the conduction band, $T$ is the temperature, $k$ is the Boltzmann's constant [30]. The plot of log $(J / E)$ versus $E^{1 / 2}$ is linear, as shown in Figure 7(b), and, therefore, the oxide conduction is Pool-Frenkel emission. It 
is found that the hydrogen ambient drastically changes the conduction mechanism of MIS Pt-GaN diodes with a $\mathrm{SiO}_{2}$ dielectric, as shown in Figures $7(\mathrm{a}, \mathrm{b})$. For MIS Pt-GaN diodes with a $\mathrm{Si}_{\mathrm{x}} \mathrm{N}_{\mathrm{y}}$ dielectric, the measured $I-V$ data in a $\mathrm{N}_{2}$ or $\mathrm{H}_{2}$ ambient were fitted using the Pool-Frenkel emission model, as shown in Figure 7(c). Figure 7(c) shows a linear relation, suggesting that the dielectric conduction is Pool-Frenkel emission. The $\mathrm{Si}_{\mathrm{x}} \mathrm{N}_{\mathrm{y}}$ dielectric is well known for showing Pool-Frenkel emission [28,31,32], consistent with the result shown in Figure 7(c). The Pool-Frenkel emission is due to emission of trapped electrons into the conduction band. The supply of electrons from the traps is through thermal excitation. For trap states with Coulomb potentials, the expression is similar to that of the Schottky emission. The barrier height, however, is the depth of the trap potential well. The barrier reduction is larger than in the case of Schottky emission by a factor of two, since the barrier lowering is twice as large due to the immobility of the positive charge [33]. The principal defect in the band gap of $\mathrm{Si}_{\mathrm{x}} \mathrm{N}_{\mathrm{y}}$ was reported to be the silicon dangling bond [31]. The hydrogen ambient does not change the conduction mechanism for MIS Pt-GaN diodes with a $\mathrm{Si}_{\mathrm{x}} \mathrm{N}_{\mathrm{y}}$ dielectric, as shown in Figure 5(b).

Figure 7. (a) FN plot for MIS Pt-GaN diodes with a $\mathrm{SiO}_{2}$ dielectric in a $\mathrm{N}_{2}$ ambient.

(b) Pool-Frenkel plot for MIS Pt-GaN diodes with a $\mathrm{SiO}_{2}$ dielectric in a $\mathrm{H}_{2}$ ambient.

(c) Pool-Frenkel plot for MIS Pt-GaN diodes with a $\mathrm{Si}_{\mathrm{x}} \mathrm{N}_{\mathrm{y}}$ dielectric in a $\mathrm{N}_{2}$ ambient Reproduced with permission from Reference [22]. Copyright 2010, American Institute of Physics.
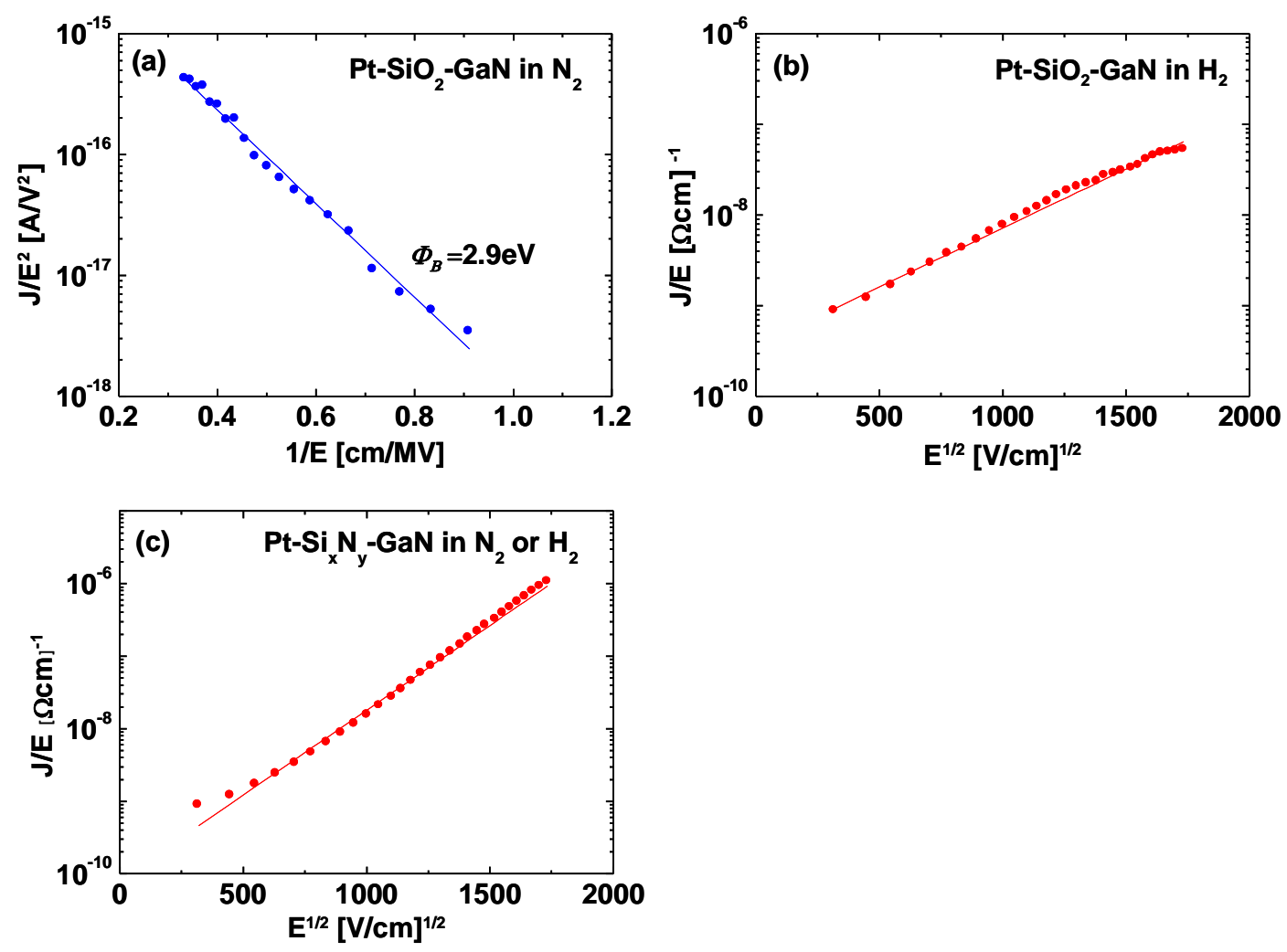

Figures $8(\mathrm{a}, \mathrm{b})$ show room-temperature $C$ - $V$ characteristics at $10 \mathrm{kHz}$ of the MIS Pt-GaN diodes with both $\mathrm{SiO}_{2}$ and $\mathrm{Si}_{\mathrm{x}} \mathrm{N}_{\mathrm{y}}$ dielectrics in a $\mathrm{N}_{2}$ ambient and the response to the exposure to $1 \% \mathrm{H}_{2}$ in $\mathrm{N}_{2}$, respectively. Bias voltage was swept from accumulation to depletion. 
Note that the capacitances in the accumulation region for MIS Pt-GaN diodes with a $\mathrm{Si}_{\mathrm{x}} \mathrm{N}_{\mathrm{y}}$ dielectric is about twice as large as those for MIS Pt-GaN diodes with a $\mathrm{SiO}_{2}$ dielectric, consistent with their dielectric constants that are 3.8-4.2 for $\mathrm{SiO}_{2}$ and 7.5 for $\mathrm{Si}_{\mathrm{x}} \mathrm{N}_{\mathrm{y}}$, respectively. As shown in Figure 8(a), for MIS Pt-GaN diodes with a $\mathrm{SiO}_{2}$ dielectric, the $C-V$ curve in $\mathrm{H}_{2}$ significantly shifts toward negative bias values. The capacitance at each value of bias is just shifted by the difference of a constant voltage so that the shape of the $C$ - $V$ curve is unaltered. These $C-V$ curves are usually explained by hydrogen-induced dipole layer formed in the metal-dielectric interface [12]. That is, the atomic hydrogen formed on the Pt surface diffuses through the metal film and is trapped at the metal-insulator interface where a polarized layer is formed. The hydrogen response $\Delta V$ can be expressed as:

$$
\Delta V=\frac{n_{i} \mu}{\varepsilon}
$$

where $n_{i}$ is the concentration of hydrogen atoms at the interface, $\mu$ is the effective dipole moment per trapped hydrogen atom, $\varepsilon$ is the permittivity [34]. The hydrogen-induced shift in the $C-V$ curves, $\Delta V$, for MIS Pt-GaN diodes with a $\mathrm{SiO}_{2}$ dielectric is $1.0 \mathrm{~V}$, as shown in Figure 8(a). This value is much larger than the $C-V$ curve shift of $0.3 \mathrm{~V}$ for $\mathrm{Pt}-\mathrm{AlGaN} / \mathrm{GaN}$ Schottky barrier diodes at the similar experimental condition, [as shown in Figure 12(a)], reflecting the drastic $I$ - $V$ changes in MIS Pt-GaN diodes with a $\mathrm{SiO}_{2}$ dielectric. Based on the Equation (6), the values of $n_{i}$ and $\mu$ should depend on the properties of interfaces. In other words, hydrogen could be a probe in order to investigate the interface properties of the devices. The $C$ - $V$ curves at a measurement frequency of $1 \mathrm{MHz}$ display the similar value of shift upon exposure to hydrogen.

Figure 8. Room-temperature $C-V$ characteristics at $10 \mathrm{kHz}$ of the MIS Pt-GaN diodes with both $\mathrm{SiO}_{2}$ (a) and $\mathrm{Si}_{\mathrm{x}} \mathrm{N}_{\mathrm{y}}$ (b) dielectrics in a $\mathrm{N}_{2}$ ambient and the response to the exposure to $1 \% \mathrm{H}_{2}$ in $\mathrm{N}_{2}$. Reproduced with permission from Reference [22]. Copyright 2010, American Institute of Physics.
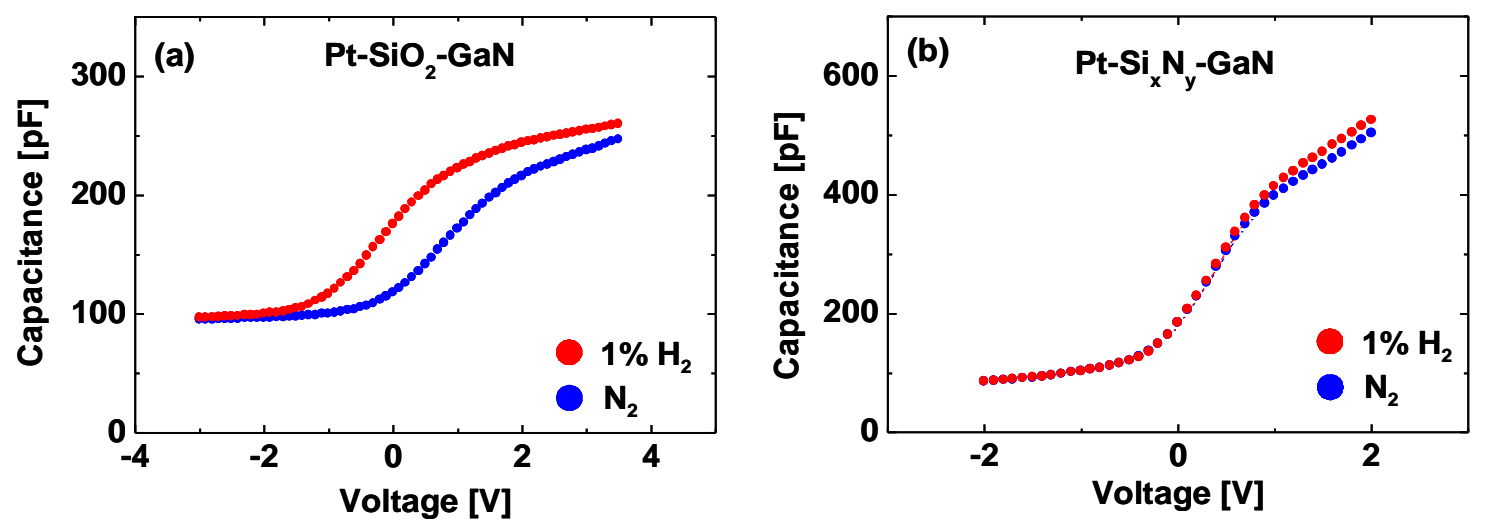

In sharp contrast, for MIS Pt-GaN diodes with a $\mathrm{Si}_{\mathrm{x}} \mathrm{N}_{\mathrm{y}}$ dielectric, the $C-V$ curve does not show any shifts upon exposure to hydrogen. Note that the capacitances in the accumulation region (the voltages ranging from 1 to $2 \mathrm{~V}$ ) in $\mathrm{H}_{2}$ show slight increase as compared with those in $\mathrm{N}_{2}$. This is probably due to the change in the dielectric constant of $\mathrm{Si}_{\mathrm{x}} \mathrm{N}_{\mathrm{y}}$ in the different ambients. The results shown in Figure $8(\mathrm{~b})$ reveal that the hydrogen-induced dipole layer is not formed in the metal-dielectric 
interface for MIS Pt-GaN diodes with a $\mathrm{Si}_{\mathrm{x}} \mathrm{N}_{\mathrm{y}}$ dielectric. These $C-V$ characteristics are quite anomalous and have not been reported yet. There is a key point that emerges from the results shown in Figure 8. Previously, it is reported that a work function decrease in the Schottky metals, such as Pd and $\mathrm{Pt}$, on exposure to hydrogen is the origin of the hydrogen sensitivity, that is, changes in the characteristics of devices $[13,14]$. If the proposed mechanism is true, the results shown in Figure 8 is not consistent, because no work function change is observed in Figure 8(b), despite using the same Schottky metal in the both devices. Note that the work function change should be reflected in the flatband voltage shifts in the $C$ - $V$ curves. Therefore, it is obvious that the interface between the metal and the semiconductor plays a critical role in the interaction of hydrogen with semiconductor devices.

Figure 9 shows room-temperature $C$ - $V$ characteristics of the MIS $\mathrm{Pt}-\mathrm{GaN}$ diodes with a $\mathrm{Si}_{\mathrm{x}} \mathrm{N}_{\mathrm{y}}$ dielectric at measurement frequencies of $10 \mathrm{kHz}, 100 \mathrm{kHz}$ and $1 \mathrm{MHz}$ in a $\mathrm{N}_{2}$ ambient and the response to the exposure to $1 \% \mathrm{H}_{2}$ in $\mathrm{N}_{2}$.

Figure 9. Room-temperature $C$ - $V$ characteristics of the MIS Pt-GaN diodes with a $\mathrm{Si}_{\mathrm{x}} \mathrm{N}_{\mathrm{y}}$ dielectric at $10 \mathrm{kHz}, 100 \mathrm{kHz}$ and $1 \mathrm{MHz}$ in a $\mathrm{N}_{2}$ ambient and the response to the exposure to $1 \% \mathrm{H}_{2}$ in $\mathrm{N}_{2}$.

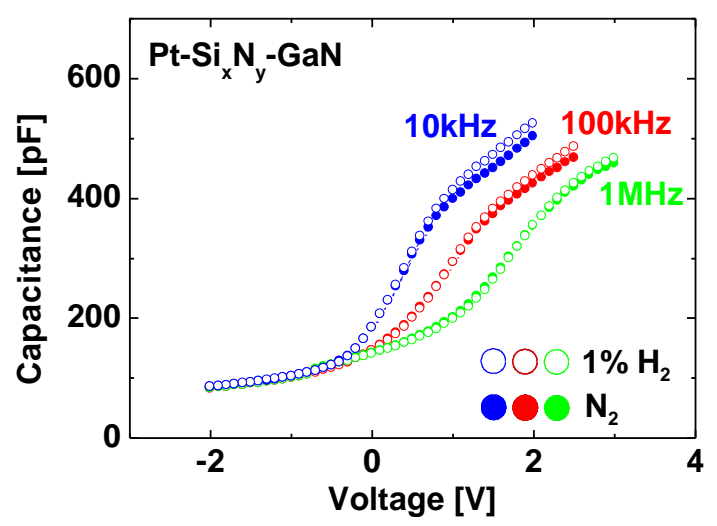

As shown in Figure 9, the $C$ - $V$ curves for MIS Pt-GaN diodes with a $\mathrm{Si}_{\mathrm{x}} \mathrm{N}_{\mathrm{y}}$ dielectric show frequency dispersion at measurement frequencies ranging from $10 \mathrm{kHz}$ to $1 \mathrm{MHz}$. Although the $C-V$ curves for MIS Pt-GaN diodes with a $\mathrm{Si}_{\mathrm{x}} \mathrm{N}_{\mathrm{y}}$ dielectric show frequency dispersion at measurement frequencies ranging from $10 \mathrm{kHz}$ to $1 \mathrm{MHz}$, all the $C-V$ curves do not show any shifts upon the exposure to hydrogen regardless of measurement frequencies. Note that these $C-V$ characteristics of the MIS Pt-GaN diodes with both $\mathrm{SiO}_{2}$ and $\mathrm{Si}_{\mathrm{x}} \mathrm{N}_{\mathrm{y}}$ dielectrics in $\mathrm{H}_{2}$ shown in Figure 8 are found to revert to the initial values upon changing the hydrogen-containing ambient into $\mathrm{N}_{2}$, just like the $I-V$ characteristics.

Although the detailed reaction mechanism of these MIS Pt-GaN diodes to hydrogen is unknown at present, the plausible mechanisms are described as follows. First, the hydrogen-induced changes in the electrical properties may be related to the number of adsorption sites for hydrogen at the metal/dielectric/semiconductor interface of the devices [35]. Second, hydrogen could be contained in both the $\mathrm{SiO}_{2}$ and $\mathrm{Si}_{\mathrm{x}} \mathrm{N}_{\mathrm{y}}$ dielectrics during the sputtering deposition, and some of the hydrogen molecules trapped at the metal/dielectric interface may affect the hydrogen detection sensitivity. Third, the $\mathrm{Si}_{\mathrm{x}} \mathrm{N}_{\mathrm{y}}$ is well known to have a high density of trap states and hence potentially suffer from charge 
trapping instabilities [32]. This property of the $\mathrm{Si}_{\mathrm{x}} \mathrm{N}_{\mathrm{y}}$ may relate to the acquired $I-V$ and $C-V$ data. Otherwise, these obtained results may be explained only by a novel reaction mechanism. Therefore, it would be important to understand the reaction mechanism underlying these phenomena, possibly leading to chemical selectivity to hydrogen. Especially, more detailed investigation of the interface states in a Schottky contact could help to interpret the reaction mechanisms at the interfaces of the MIS $\mathrm{Pt}-\mathrm{GaN}$ diodes to hydrogen.

Furthermore, $\mathrm{Si}_{\mathrm{x}} \mathrm{N}_{\mathrm{y}}$ passivation is known to be effective in improving the reliability of $\mathrm{AlGaN} / \mathrm{GaN}$ high-electron mobility transistors (HEMTs), and the stability of MIS Pt-GaN diodes with a $\mathrm{Si}_{\mathrm{x}} \mathrm{N}_{\mathrm{y}}$ dielectric exposed to hydrogen, as reported here, may be related to the excellent passivation property of $\mathrm{Si}_{\mathrm{x}} \mathrm{N}_{\mathrm{y}}$ [36].

\subsection{Low-Frequency Capacitance-Voltage Study of Hydrogen Interaction with Pt-AlGaN/GaN Schottky Barrier Diodes}

In the previous studies, high-frequency $C$ - $V$ characterization was typically employed in order to elucidate the reaction mechanism. As a result, a shift of the $C$ - $V$ curves toward negative bias values upon hydrogen exposure was observed, concluding that the formation of a dipole layer reduces the effective Schottky barrier height. The formation of the dipole layer should increase the capacitance; however, no increase of the capacitance has been reported yet. We presumed that very low frequencies are required in order to observe the proposed dipole layer and to investigate the reaction mechanism. Here, we demonstrate a clear change in the $C$ - $V$ characteristics of $\mathrm{Pt}-\mathrm{AlGaN} / \mathrm{GaN}$ SBDs exposed to hydrogen using a low frequency [37]. Typical $I-V$ characteristics of the Pt-AlGaN/GaN SBD in $\mathrm{N}_{2}$ and response to exposure to $1 \% \mathrm{H}_{2}$ in $\mathrm{N}_{2}$ at room temperature are shown in Figure 10.

Figure 10. $I-V$ characteristics of the device in $\mathrm{N}_{2}$ and response to exposure to $1 \% \mathrm{H}_{2}$ in $\mathrm{N}_{2}$ at room temperature. Reproduced with permission from Reference [37]. Copyright Wiley-VCH Verlag GmbH \& Co. KGaA.

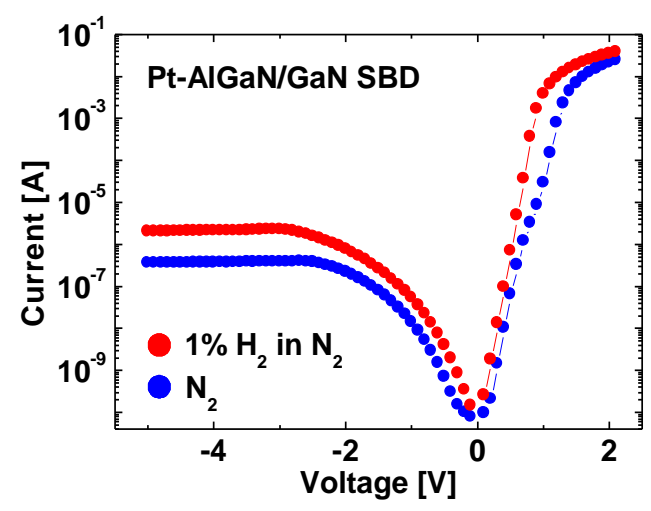

From $I-V$ measurements, good rectifier characteristics of the n-type Schottky diode were confirmed for SBD samples in both environments. The introduction of hydrogen clearly enhances the current under a given bias both in forward and reverse $I-V$ characteristics, as reported previously [38,39]. The forward $I-V$ characteristics consist of the exponential region in the low-current region and the resistance-limited region in the high-current region. The ideality factor $n$ and Schottky barrier height 
$\ddot{O}_{B}$ were calculated by applying the thermoionic emission theory to the forward $I-V$ curves. The calculated values of $n$ and $\ddot{O}_{B}$ were $2.3 \mathrm{eV}, 0.88 \mathrm{eV}$ in $\mathrm{N}_{2}$ and $1.9 \mathrm{eV}, 0.81 \mathrm{eV}$ in $1 \% \mathrm{H}_{2}$, respectively. These values are consistent with those previously reported [39]. Upon changing the hydrogen-containing ambient into $\mathrm{N}_{2}$, the $I-V$ characteristics of the Pt-AlGaN/GaN SBD are found to revert to the initial values. According to the previous literature, the reduction in the Schottky barrier height is explained as a result of the formation of a hydrogen-induced dipole layer between the metal and the semiconductor $[38,39]$.

In order to investigate the detailed mechanism of the interaction between hydrogen and $\mathrm{Pt}-\mathrm{AlGaN} / \mathrm{GaN}$ SBDs, we have conducted low frequency $G-V$ and $C-V$ characterization of $\mathrm{Pt}-\mathrm{AlGaN} / \mathrm{GaN}$ SBDs exposed to hydrogen. The $G-V$ and $C-V$ characterization was conducted with an ac modulation level of $100 \mathrm{mV}$ and frequencies ranging from $1 \mathrm{~Hz}$ to $1 \mathrm{kHz}$. Figures 11 and 12 show room-temperature $G-V$ and $C-V$ characteristics at various frequencies of the $\mathrm{Pt}-\mathrm{AlGaN} / \mathrm{GaN} \mathrm{SBD}$ in $\mathrm{N}_{2}$ and response to exposure to $1 \% \mathrm{H}_{2}$ in $\mathrm{N}_{2}$, respectively.

The $G$ - $V$ curves in Figure 11 suggest the following three issues: First, the conductance goes through a peak and approaches zero on either side. Second, the maximum values of the conductance in $\mathrm{H}_{2}$ is much higher than those in $\mathrm{N}_{2}$, which is probably related to the enhanced current under a given bias in $I-V$ characteristics upon the introduction of hydrogen, as shown in Figure 10. Third, the $G-V$ curves show frequency dependence. The peak magnitude of the conductance increases with increasing frequency in both ambients.

Figure 11. Room-temperature $G-V$ characteristics at various frequencies of the $\mathrm{Pt}-\mathrm{AlGaN} / \mathrm{GaN}$ SBD in $\mathrm{N}_{2}$ (a) and response to exposure to $1 \% \mathrm{H}_{2}$ in $\mathrm{N}_{2}$ (b).
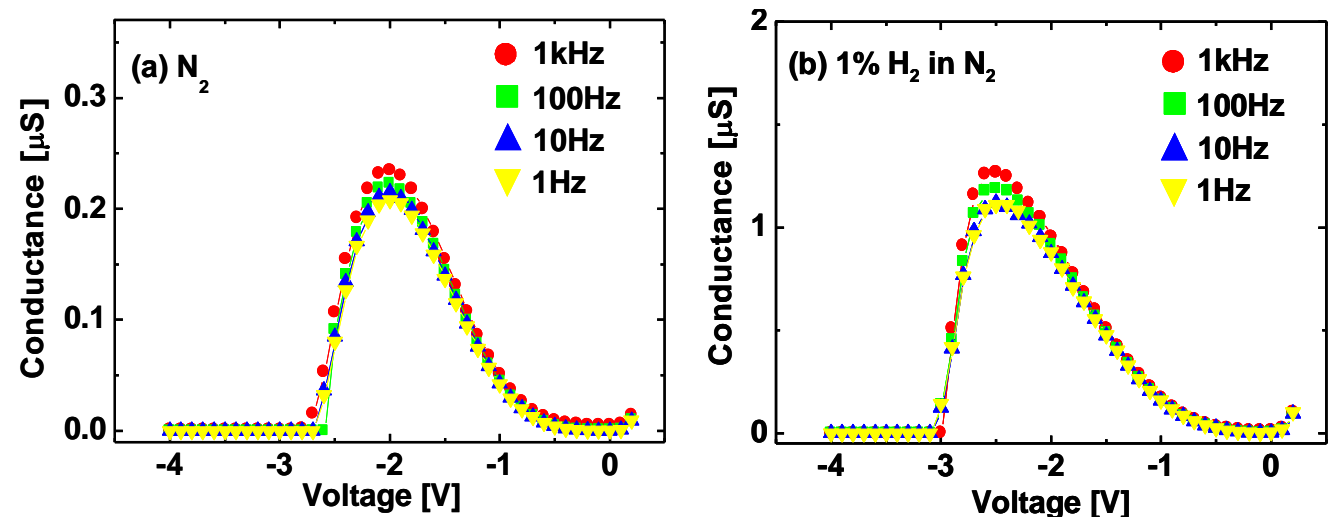

In Figure 12(a), the $C-V$ characteristics in $\mathrm{N}_{2}$ can be roughly classified into two diode bias $\left(V_{G}\right)$ regions: (i) $-1.5 \mathrm{~V} \leq V_{G}$, (ii) $V_{G}<-1.5 \mathrm{~V}$. In region (i), the capacitance is almost flat due to only small changes induced by applying $V_{G}$, where the depletion layer width is calculated to be $22.2-23.3 \mathrm{~nm}$, in reasonable agreement with the $\mathrm{AlGaN}$ layer thickness. The almost flat portion of the capacitance is interpreted as the dc depletion of 2DEG by negative dc voltages. In region (ii), the capacitance rapidly decreases with decreasing $V_{G}$ down to $-2.8 \mathrm{~V}$ which is the pinch-off voltage, $V_{T H}$. This region corresponds to the depletion of GaN after almost complete pinch-off of 2DEG. At a frequency of $1 \mathrm{kHz}$, the $C-V$ curve in $\mathrm{H}_{2}$ shifts toward negative bias values, as reported previously [38]. As the frequency decreases from $1 \mathrm{kHz}$ to $1 \mathrm{~Hz}$, the capacitance in $\mathrm{H}_{2}$ dramatically increases and the 
oscillation of the capacitance is observed, as shown in Figure 12. These $C-V$ characteristics are quite anomalous and have not been reported so far. In sharp contrast, the $C-V$ curves in $\mathrm{N}_{2}$ do not change significantly over all the frequencies ranging from $1 \mathrm{kHz}$ to $1 \mathrm{~Hz}$. Note that these $C-V$ characteristics of the $\mathrm{Pt}-\mathrm{AlGaN} / \mathrm{GaN}$ SBD in $\mathrm{H}_{2}$ shown in Figure 12 are found to revert to the initial values upon changing the hydrogen containing ambient into $\mathrm{N}_{2}$, just like the $I-V$ characteristics. There are several key points that emerge from the results shown in Figure 12. First, at a frequency of $1 \mathrm{kHz}$, the $C-V$ curve in $\mathrm{H}_{2}$ does not reflect any polarization because the capacitance should increase when polarization is formed in the dielectric material [40]. In Figure 12(a), the capacitance at each value of bias is just shifted by the difference of their pinch-off voltages so that the shape of the $C-V$ curve is unaltered. These $C-V$ curves could be explained by positive fixed charge in the $\mathrm{Pt}-\mathrm{AlGaN}$ interface [41]. Second, at a frequency of $1 \mathrm{~Hz}$, the capacitance in $\mathrm{H}_{2}$ dramatically increases with decreasing $V_{G}$ down to $V_{T H}$. This anomalous $C-V$ curve would not be attributed to mobile ionic charge because mobile ionic charge can be detected in $C-V$ characteristics even at much higher frequency like $1 \mathrm{MHz}$ [41]. Third, the capacitance in region (ii), e.g., at a bias voltage of $-2 \mathrm{~V}$, at a frequency of $1 \mathrm{~Hz}$ in $\mathrm{N}_{2}$ is slightly higher than that at a frequency of $1 \mathrm{kHz}$. This is probably due to the tiny amount of remnant hydrogen in the devices. Here, no thermal treatment was performed in order to expel the remnant hydrogen from the devices prior to the experiment. Fourth, generally speaking, interfacial polarization, which occurs when mobile charge carriers are impeded by a physical barrier that inhibits charge migration, could produce such an increased capacitance in $\mathrm{H}_{2}$ at a low frequency [40]. Although little is known about interfacial polarization in the case of hydrogen interaction with semiconductor devices, hydrogen-related dipoles may have the function of interfacial polarization. Adsorbed hydrogen on the AlGaN surface is positively charged and fixed on the surface, forming a dipole layer. Sufficiently low ac oscillations switch the polarity of dipoles, leading to the significant increase in the capacitance. Fifth, as for the $C-V$ curves at low frequencies, the capacitance in $\mathrm{H}_{2}$ dramatically increases with decreasing $V_{G}$ down to $V_{T H}$ as compared with those in $\mathrm{N}_{2}$ although the capacitance at zero bias has nearly the same value both in $\mathrm{N}_{2}$ and $\mathrm{H}_{2}$, suggesting that the alignment of electric dipoles by applied biases may be related. A similar phenomenon is observed in ferroelectric materials in which the domains can switch from one direction of spontaneous alignment to another when an electric filed is applied, giving rise to large changes in the polarization and dielectric constant [42]. Furthermore, the oscillation of the capacitance observed in the $C-V$ curve at $1 \mathrm{~Hz}$ in $\mathrm{H}_{2}$ may be explained by the alignment of hydrogen-related dipoles when the ac oscillation is applied, i.e., the ac oscillation tries to switch the polarity of dipoles, but some of them cannot follow the oscillation simultaneously, resulting in the capacitance oscillation as a function of the applied bias voltages. In addition, surface charges on AlGaN may influence the dipole formation and alter $C-V$ curves, implying that low-frequency $C-V$ measurements could be useful for monitoring the surface states of AlGaN.

$I-V$ and $C-V$ characteristics of the Pt-AlGaN/GaN SBD for much lower concentration of hydrogen, which was $100 \mathrm{ppm} \mathrm{H}_{2}$ in $\mathrm{N}_{2}$, were performed at room temperature. Figure 13 shows $I-V$ characteristics of the device in $\mathrm{N}_{2}$ and response to exposure to $100 \mathrm{ppm}_{2}$ in $\mathrm{N}_{2}$ at room temperature. Comparing Figure 13 with Figure 10, the current enhancement under a given bias is different, i.e., $1 \%$ $\mathrm{H}_{2}$ enhances more current under a given bias than $100 \mathrm{ppm} \mathrm{H}_{2}$ does both in forward and reverse $I-V$ characteristics. 
Figure 12. $C-V$ characteristics at $1 \mathrm{kHz}$ (a), $100 \mathrm{~Hz}$ (b), $10 \mathrm{~Hz}$ (c) and $1 \mathrm{~Hz}$ (d) of the $\mathrm{Pt}-\mathrm{AlGaN} / \mathrm{GaN} \mathrm{SBD}$ in $\mathrm{N}_{2}$ and response to the exposure to $1 \% \mathrm{H}_{2}$ in $\mathrm{N}_{2}$ at room temperature. Reproduced with permission from Reference [37]. Copyright Wiley-VCH Verlag GmbH \& Co. KGaA.
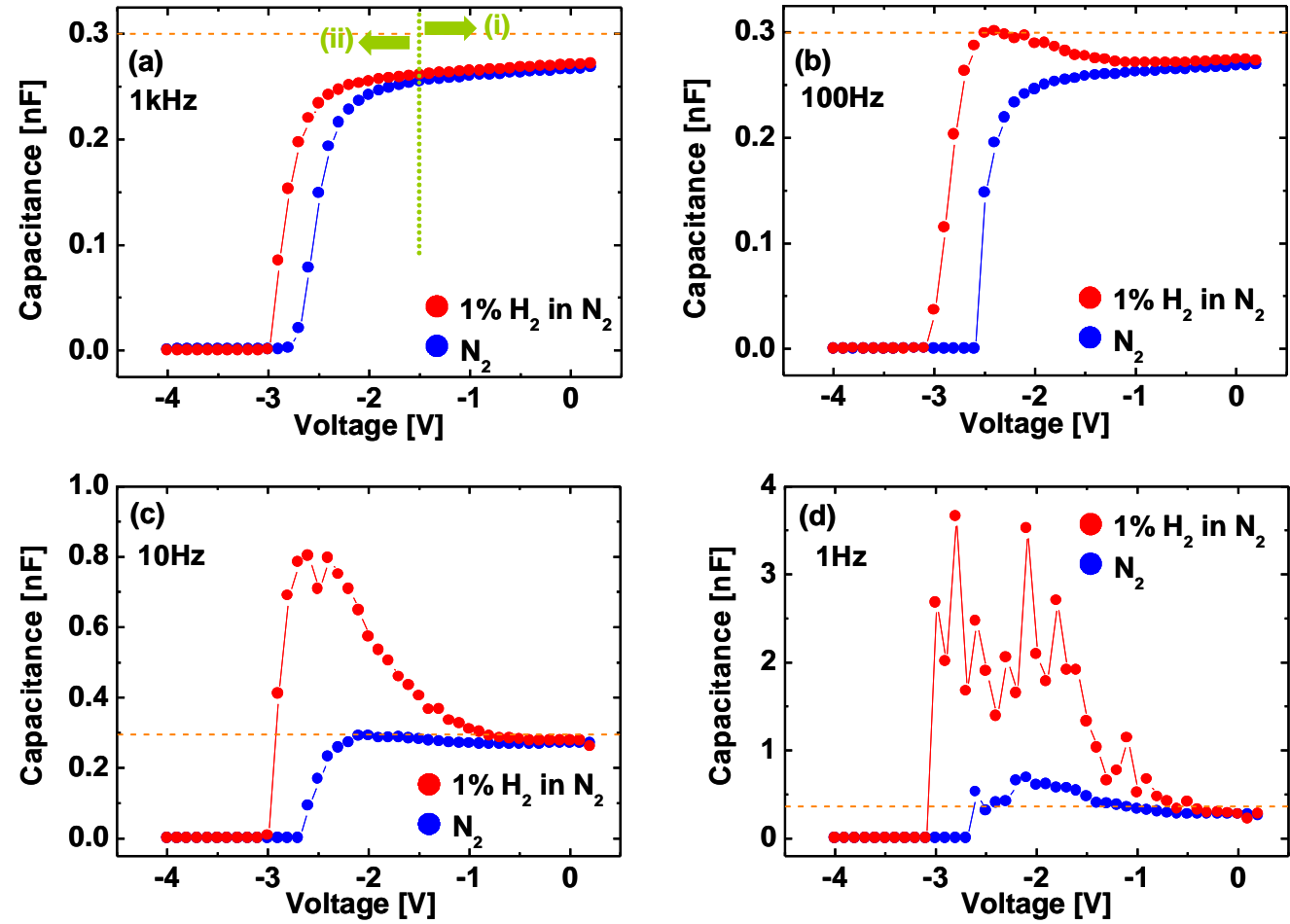

Figure 13. $I-V$ characteristics of the device in $\mathrm{N}_{2}$ and response to exposure to $100 \mathrm{ppm}_{2}$ in $\mathrm{N}_{2}$ at room temperature.

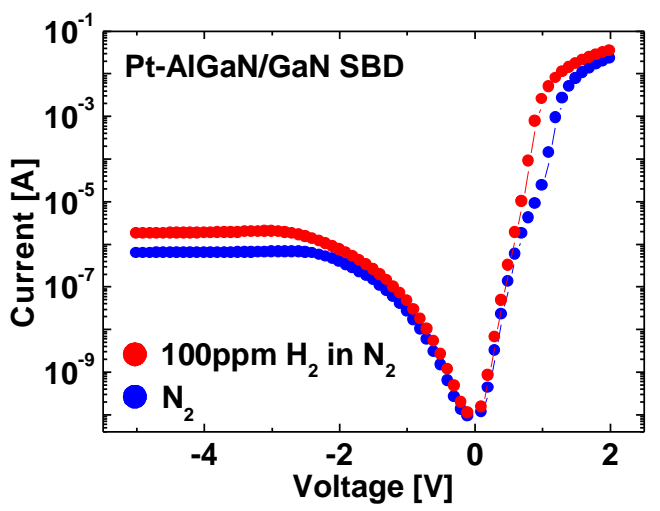

Figure 14 shows $C$ - $V$ characteristics at $1 \mathrm{kHz}(\mathrm{a}), 100 \mathrm{~Hz}$ (b), $10 \mathrm{~Hz}$ (c) and $1 \mathrm{~Hz}$ (d) of the

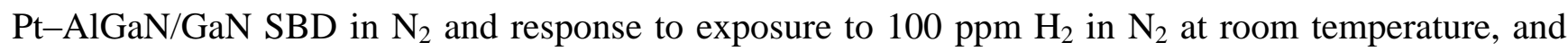
Figure 15 shows time evolution of $C$ - $V$ characteristics in $100 \mathrm{ppm} \mathrm{H}_{2}$ at $1 \mathrm{~Hz}$. 
Figure 14. $C-V$ characteristics at $1 \mathrm{kHz}$ (a), $100 \mathrm{~Hz}$ (b), $10 \mathrm{~Hz}$ (c) and $1 \mathrm{~Hz}$ (d) of the $\mathrm{Pt}-\mathrm{AlGaN} / \mathrm{GaN} \mathrm{SBD}$ in $\mathrm{N}_{2}$ and response to exposure to $100 \mathrm{ppm} \mathrm{H}_{2}$ in $\mathrm{N}_{2}$ at room temperature.
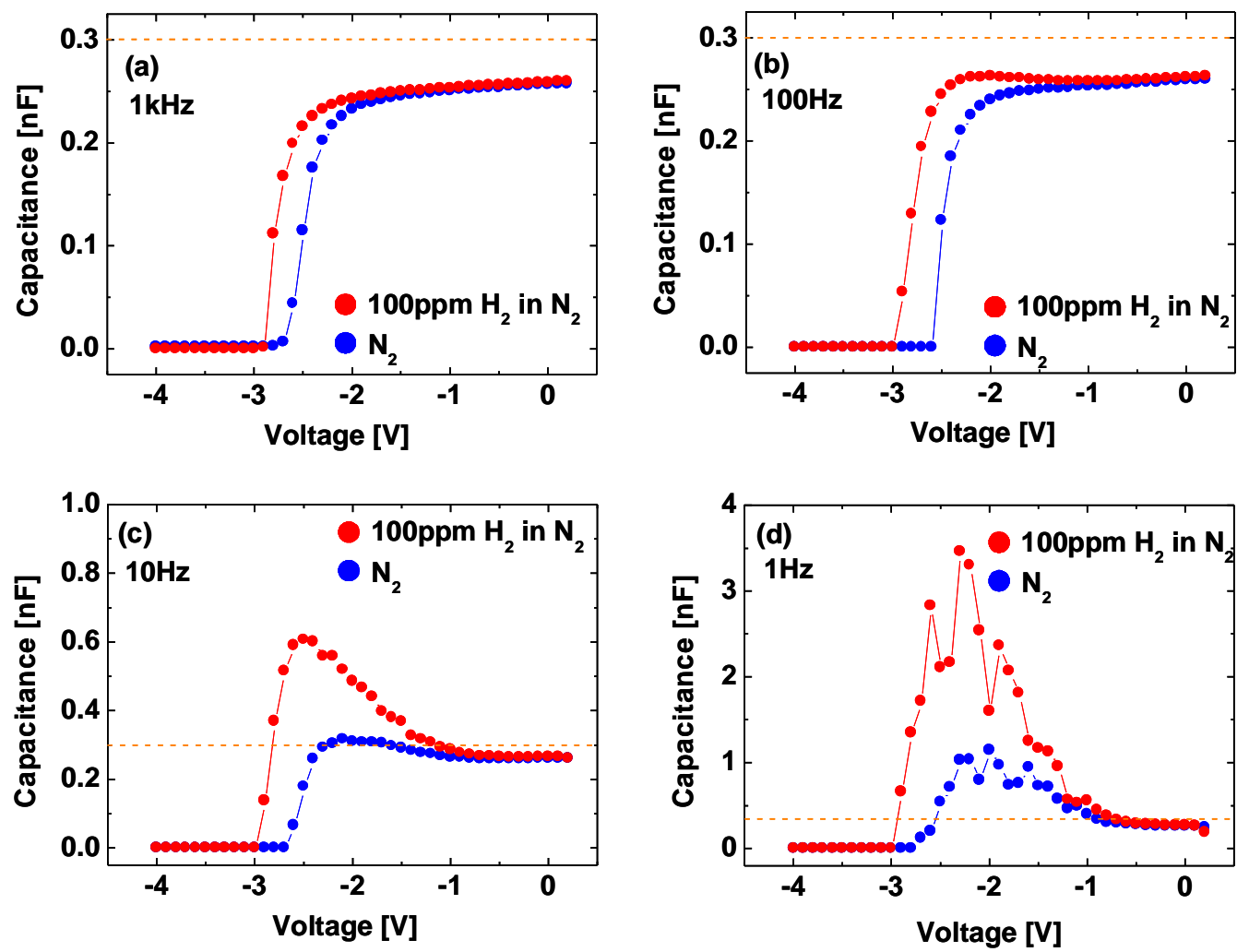

Note that the $C-V$ characteristics with $100 \mathrm{ppm}_{2}$ result in similar curves to those with $1 \% \mathrm{H}_{2}$, as

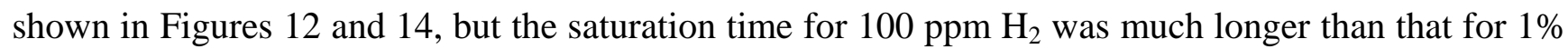
$\mathrm{H}_{2}$. As shown in Figure 15, upon $\mathrm{H}_{2}$ exposure, the capacitances increase till $\sim 60$ min and saturate after 60 min upon $\mathrm{H}_{2}$ exposure.

Figure 15. Time evolution of $C$ - $V$ characteristics in $100 \mathrm{ppm}_{2}$ at $1 \mathrm{~Hz}$.

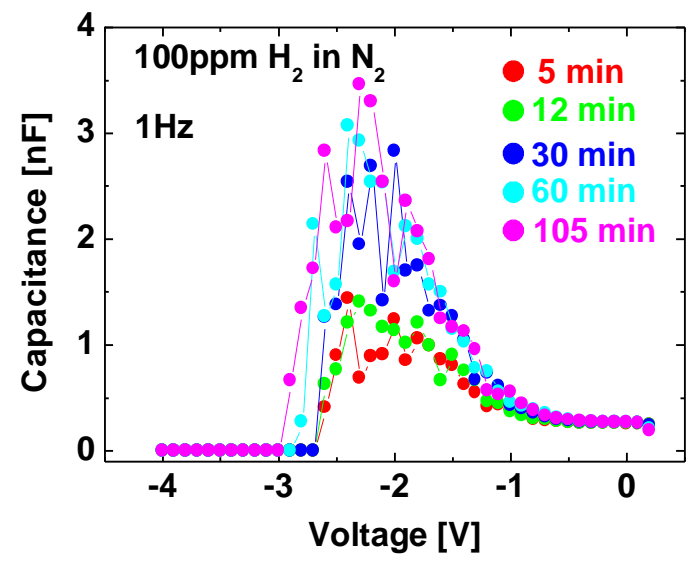

By sharp contrast, at $1 \% \mathrm{H}_{2}$, capacitances saturate instantaneously. In low $\mathrm{H}_{2}$ concentrations like $100 \mathrm{ppm}$, it takes more than $60 \mathrm{~min}$ to saturate the $C-V$ characteristics (and also $I-V$ characteristics), as shown in Figure 15, suggesting that hydrogen-induced dipole formation needs longer time in lower 
concentration of a hydrogen ambient. But, using low-frequency $C$ - $V$ characterization leads to clear detection of $100 \mathrm{ppm}$ hydrogen even at room temperature where it is hard to detect hydrogen by using conventional $I-V$ characterization, suggesting that low-frequency $C-V$ method would be effective in detecting very low concentration of hydrogen.

\section{Conclusions and Future Work}

The hydrogen sensing mechanism of nitride-based semiconductor diodes is investigated, focusing on the metal/semiconductor interfaces. Electrical characterization of Pt-GaN Schottky diodes shows the devices fabricated on annealed surfaces display the similar in hydrogen detection sensitivity to those on as-grown surfaces unlike the difference of the PL spectra, implying that the surface defects of GaN do not play a critical role in hydrogen sensing characteristics of Pt-GaN Schottky diodes. However, dielectrics between the metal and GaN surfaces are found to cause dramatic change of hydrogen detection performance, suggesting that the realization of chemical selectivity to hydrogen is possible.

Exposure of $\mathrm{Pt}-\mathrm{SiO}_{2}-\mathrm{GaN}$ diodes to hydrogen at room temperature is found to change the conduction mechanisms from FN tunneling to Pool-Frenkel emission. In sharp contrast, $\mathrm{Pt}-\mathrm{Si}_{\mathrm{x}} \mathrm{N}_{\mathrm{y}}-\mathrm{GaN}$ diodes exhibit Pool-Frenkel emission in nitrogen and do not show any change in the conduction mechanism upon exposure to hydrogen. The $C$ - $V$ curve for $\mathrm{Pt}-\mathrm{Si}_{\mathrm{x}} \mathrm{N}_{\mathrm{y}}-\mathrm{GaN}$ diodes also does not show any shifts upon the exposure to hydrogen. Although the detailed reaction mechanism of these MIS Pt-GaN diodes to hydrogen is unknown at present, these results suggest that the work function change in the Schottky metal is not responsible mechanism for the hydrogen sensitivity. The interface between the metal and semiconductor plays a critical role in the interaction of hydrogen with semiconductor devices. Detailed investigation for these phenomena would lead to the elucidation of the interaction mechanism of hydrogen with semiconductor devices. Furthermore, hydrogen could be a probe in order to investigate the interface properties of the devices.

A significant increase in the capacitance was observed at a low frequency in Pt-AlGaN/GaN SBD upon exposure to hydrogen. This could be explained by interfacial polarization which is attributable to hydrogen related dipoles, i.e., sufficiently low ac oscillations switch the polarity of dipoles, leading to an increase in the capacitance. In addition, using low-frequency $C$ - $V$ characterization leads to clear detection of $100 \mathrm{ppm}$ hydrogen even at room temperature where it is hard to detect hydrogen by using conventional $I-V$ characterization, suggesting that low-frequency $C-V$ method would be effective in detecting very low concentration of hydrogen.

Future work will involve the following three points: First, more detailed interaction mechanism of hydrogen with nitride-based semiconductor devices should be studied. In this report, only the interaction of hydrogen with nitride-based semiconductor diodes at room temperature was investigated by using electrical methods. Investigation varying the gases, measurement temperatures, device structures and measurement methods may lead to the more specific elucidation of the interaction mechanism $[43,44]$. Second, fabrication of sensors with higher performances is required. The following list gives both constraints and requirements for an ideal detector: (i) Chemically selective, (ii) reversible, (iii) fast, (iv) highly sensitive, (v) durable, and (vi) non-contaminating and non-poisoning; other constraints involve requirements for (vii) simple operation, (viii) small size 
(portability), (ix) simple fabrication, (x) relative temperature insensitivity, and (xi) low noise. For example, no literatures previously report semiconductor sensors with selectivity to hydrogen. The elucidation of interaction mechanism of hydrogen with semiconductor devices may lead to realization of the selectivity. Third, from the point of view of the interaction mechanism of hydrogen with semiconductor materials and devices, relation with other semiconductor materials, such as $\mathrm{ZnO}, \mathrm{SiC}$ and diamond should be clarified. For example, adsorbed hydrogen on $\mathrm{ZnO}, \mathrm{SiC}$ or diamond is found to change their electrical properties drastically [45-47]. Similar phenomenon may be observed in nitride-based semiconductors, possibly leading to a new interaction mechanism of hydrogen with semiconductors.

\section{Acknowledgements}

This study was partly supported by the Grant-in-Aid for Young Scientists (B) of the Ministry of Education, Culture, Sports, Science and Technology (MEXT). I appreciate the contributions of Y. Nakano and Y. Sumida to this work.

\section{References and Notes}

1. Christofides, C.; Mandelis, A. Solid-state sensors for trace hydrogen gas detection. J. Appl. Phys. 1990, 68, R1-R30.

2. Pearton, S.J.; Ren, F.; Wang, Y.L; Chu, B.H.; Chen, K.H.; Chang, C.Y.; Lim, W.; Lin, J.; Norton, D.P. Recent advances in wide bandgap semiconductor biological and gas sensors. Progr. Mater. Sci. 2010, 55, 1-59.

3. Pearton, S.J.; Kang, B.S.; Kim, S.; Ren, F.; Gila, B.P.; Abernathy, C.R; Lin, J.; Chu, S.N.G. GaN-based diodes and transistors for chemical, gas, biological and pressure sensing. J. Phys. Condens. Matter 2004, 16, R961-R994.

4. Trinchi, A.; Kandasamy, S.; Wlodarski, W. High temperature field effect hydrogen and hydrocarbon gas sensors based on SiC MOS devices. Sens. Actuat. B 2008, 133, 705-716.

5. Soo, M.T.; Cheong, K.Y.; Noor, A.F.M. Advances of SiC-based MOS capacitor hydrogen sensors for harsh environment applications. Sens. Actuat. B 2010, 151, 39-55.

6. Schalwig, J.; Müller, G.; Karrer, U.; Eickhoff, M.; Ambacher, O.; Stutzmann, M.; Görgens, L.; Dollinger, G. Hydrogen response mechanism of Pt-GaN Schottky diodes. Appl. Phys. Lett. 2002, $80,1222-1224$.

7. Winzer, A.T.; Goldhahn, R.; Gobsch, G.; Dadgar, A.; Krost, A.; Weidemann, O.; Stutzmann, M.; Eickhoff, M. Electroreflectance spectroscopy of Pt/AlGaN/GaN heterostructures exposed to gaseous hydrogen. Appl. Phys. Lett. 2006, 88, 024101.

8. Lundström, I.; Sundgren, H.; Winquist, F.; Eriksson, M.; Rülcker, C.K.; Spetz, A.L. Twenty-five years of field effect gas sensor research in Linköping. Sens. Actuat. B 2007, 121, 247-262.

9. Lundström, I.; DiStefano, T. Influence of hydrogen on $\mathrm{Pt}-\mathrm{SiO}_{2}-\mathrm{Si}$ structures. Solid State Commun. 1976, 19, 871-875.

10. Lundström, I.; Shivaraman, M.S.; Svensson, C. Chemical reactions on palladium surfaces studied with Pd-MOS structures. Surf. Sci. 1977, 64, 497-519. 
11. Söderberg, D.; Lundtröm. I. Surface and interface dipoles on catalytic metal films. Solid State Commun. 1980, 35, 169-174.

12. Ekedahl, L.G.; Eriksson, M.; Lundström, I. Hydrogen sensing mechanisms of metal-insulator interfaces. Acc. Chem. Res. 1998, 31, 249-256.

13. Petty, M.C. Conduction mechanisms in $\mathrm{Pd} / \mathrm{SiO}_{2} / \mathrm{n}-\mathrm{Si}$ Schottky diode hydrogen detectors. Solid State Electron. 1986, 29, 89-97.

14. Nakamura, S.; Ohsono, T.; Takahashi, N.; Okumura, T. Kelvin-probe characterization of hydrogen-sensitive palladium/notride semiconductors contacts. In Proceedings of The 8th International Conference on Nitride Semiconductors, Jeju, Korea, 18-23 October 2009; Volume 1, pp. 6-7.

15. Weidemann, O.; Hermann, M.; Steinhoff, G.; Wingbrant, H.; A. Spetz, A.L.; Stutzmann, M.; Eickhoff, M. Influence of surface oxides on hydrogen-sensitive Pd:GaN Schottky diodes. Appl. Phys. Lett. 2003, 83, 773-775.

16. Kang, B.S.; Kim, S.; Ren, F.; Gila, B.P.; Abernathy, C.R.; Pearton, S.J. Comparison of MOS and Schottky W/Pt-GaN diodes for hydrogen detection. Sens. Actuat. B 2005, 104, 232-236.

17. Irokawa, Y.; Sakuma, Y.; Sekiguchi, T. Effect of dielectrics on hydrogen detection sensitivity of metal-insulator-semiconductor Pt-GaN diodes. Jpn. J. Appl. Phys. 2007, 46, 7714-7716.

18. Yan, J.T.; Lee, C.T. Improved detection sensitivity of $\mathrm{Pt} / \mathrm{\beta}_{-} \mathrm{Ga}_{2} \mathrm{O}_{3} / \mathrm{GaN}$ hydrogen sensor diode. Sens. Actuat. B 2009, 143, 192-197.

19. Chiu, S.Y.; Huang, H.W.; Huang, T.H.; Liang, K.C.; Liu, K.P.; Tsai, J.H.; Lour. W.S. Comprehensive study of $\mathrm{Pd} / \mathrm{GaN}$ metal-semiconductor-metal hydrogen sensors with symmetrically bi-directional sensing performance. Sens. Actuat. B 2009, 138, 422-427.

20. Chiu, S.Y.; Liang, K.C.; Huang, T.H.; Liu, K.P.; Huang, H.W.; Tsai, J.H.; Lour, W.S. GaN sensors with metal-oxide mixture for sensing hydrogen-containing gases of ultralow concentration. Jpn. J. Appl. Phys. 2009, 48, 041002.

21. Chang, C.F.; Tsai, T.H.; Chen, H.I.; Lin, K.W.; Chen, T.P.; Chen, L.Y.; Liu, Y.C.; Liu, W.C. Hydrogen sensing properties of a $\mathrm{Pd} / \mathrm{SiO}_{2} / \mathrm{AlGaN}$-based MOS diode. Electrochem. Commun. 2009, 11, 65-67.

22. Irokawa, Y. Hydrogen-induced change in the electrical properties of metal-insulatorsemiconductor Pt-GaN diodes. J. Appl. Phys. 2010, 108, 094501.

23. Nakagomi, S.; Spetz, A.L.; Lundstrom, I.; Tobias, P. Electrical characterization of carbon monoxide sensitive high temperature sensor diode based on catalytic metal gate-insulator-silicon carbide structure. IEEE Sens. J. 2002, 2, 379-386.

24. Schalwig, J.; Müller, G.; Eickhoff, M.; Ambacher, O.; Stutzmann, M. Group III-nitride-based gas sensors for combustion monitoring. Mater. Sci. Eng. B 2002, 93, 207-214.

25. Oh, E.; Kim, B.; Park, H.; Park, Y. Effect of surface layer on optical properties of GaN and $\mathrm{In}_{\mathrm{x}} \mathrm{Ga}_{1-\mathrm{x}} \mathrm{N}$ upon thermal annealing. Appl. Phys. Lett. 1998, 73, 1883-1885.

26. Matsuo, K.; Negoro, N.; Kotani, J.; Hashizume, T.; Hasegawa, H. Pt Schottky diode gas sensors formed on GaN and AlGaN/GaN heterostructure. Appl. Surf. Sci. 2005, 244, 273-276.

27. Schroder, D.K. Semiconductor Material and Device Characterization, 3rd ed.; Wiley: New York, NY, USA, 2006; pp. 728-730. 
28. Kim, E.; Soejima, N.; Watanabe, Y.; Ishiko, M.; Kachi, T. Electrical Properties of Metal-Insulator-Semiconductor Capacitors on Freestanding GaN Substrate. Jpn. J. Appl. Phys. 2010, 49, 04DF08.

29. Robertson, J.; Falabretti, B. Band offsets of high K gate oxides on III-V semiconductors. J. Appl. Phys. 2006, 100, 014111.

30. Sze, S.M.; Ng, K.K. Physics of Semiconductor Devices, 3rd ed.; Wiley: New York, NY, USA, 2007; pp. 357-360.

31. Lowe, A.J.; Powell, M.J.; Elliott, S.R. The electronic properties of plasma-deposited films of hydrogenated amorphous $\operatorname{SiN}_{\mathrm{x}}(0<\mathrm{x}<1.2)$. J. Appl. Phys. 1986, 59, 1251-1258.

32. Powell, M.J. Charge trapping instabilities in amorphous silicon-silicon nitride thin-film transistors. Appl. Phys. Lett. 1983, 43, 597-599.

33. Sze, S.M.; Ng, K.K. Physics of Semiconductor Devices, 3rd ed.; Wiley: New York, NY, USA, 2007; pp. 227-229.

34. Eriksson, M.; Salomonsson, A; Lundström, I; Briand, D.; Åbom, A.E. The influence of the insulator surface properties on the hydrogen response of field-effect gas sensors. J. Appl. Phys. 2005, 98, 034903.

35. Fogelberg, J.; Eriksson, M.; Dannetun, H.; Petersson, L.G. Kinetic modeling of hydrogen adsorption/absorption in thin films on hydrogen-sensitive field-effect devices: Observation of large hydrogen-induced dipoles at the $\mathrm{Pd}-\mathrm{SiO}_{2}$ interface. J. Appl. Phys. 1995, 78, 988-996.

36. Kim, H.; Thompson, R.M.; Tilak, V.; Prunty, T.R.; Shealy, J.R.; Eastman, L.F. Effects of SiN passivation and high-electric field on AlGaN-GaN HFET degradation. IEEE Electron. Device Lett. 2003, 24, 421-423.

37. Irokawa, Y.; Matsuki, N.; Sumiya, M.; Sakuma, Y.; Sekiguchi, T.; Chikyo, T.; Sumida, Y.; Nakano, Y. Low-frequency capacitance-voltage study of hydrogen interaction with Pt-AlGaN/GaN Schottky barrier diodes. Phys. Status Solidi RRL 2009, 3, 266-268.

38. Hasegawa, H.; Akazawa, M. Mechanism and control of current transport in GaN and AlGaN Schottky barriers for chemical sensor applications. Appl. Surf. Sci. 2008, 254, 3653-3666.

39. Miyoshi, M.; Kuraoka, Y.; Asai, K.; Shibata, T.; Tanaka, M.; Egawa, T. Electrical characterization of $\mathrm{Pt} / \mathrm{AlGaN} / \mathrm{GaN}$ Schottky diodes grown using AlN template and their application to hydrogen gas sensors. J. Vac. Sci. Technol. 2007, B25, 1231-1235.

40. Hench, L.L.; West, J.K. Principles of Electronic Ceramics, 1st ed.; Wiley: New York, NY, USA, 1989; pp. 185-236.

41. Nicollian, E.H.; Brews, J.R. MOS (Metal Oxide Semiconductor) Physics and Technology, 1st ed.; Wiley: New York, NY, USA, 2003; pp. 423-491.

42. Pintilie, L.; Lisca, M.; Alexe, M. Polarization reversal and capacitance-voltage characteristic of epitaxial $\mathrm{Pb}(\mathrm{Zr}, \mathrm{Ti}) \mathrm{O}_{3}$ layers. Appl. Phys. Lett. 2005, 86, 192902.

43. Wang, Y.L.; Ren, F.; Zhang, U.; Sun, Q.; Yerino, C.D.; Ko, T.S.; Cho, Y.S.; Lee, I.H.; Han, J.; Pearton, S.J. Improved hydrogen detection sensitivity in N-polar GaN Schottky diodes. Appl. Phys. Lett. 2009, 94, 212108.

44. Lo, C.F; Chang, C.Y; Chu, B.H.; Pearton, S.J.; Dabiran, A.; Chow, P.P.; Ren, F. Effect of humidity on hydrogen sensitivity of Pt-gated AlGaN/GaN high electron mobility transistor based sensors. Appl. Phys. Lett. 2010, 96, 232106. 
45. Wang, Y.; Meyer, B.; Yin, X.; Kunat, M.; Langenberg, D.; Traeger, F.; Birkner, A.; Wöll, C. Hydrogen Induced Metallicity on the $\mathrm{ZnO}(10 \overline{1} 0)$ Surface. Phys. Rev. Lett. 2005, 95, 266104.

46. Derycke, V.; Soukiassian, P.G.; Amy, F.; Chabal, Y.J.; D'angelo, M.D.; Enriquez, H.B.; Silly, M.G. Nanochemistry at the atomic scale revealed in hydrogen-induced semiconductor surface metallization. Nature Mater. 2003, 2, 253-258.

47. Hayashi, K.; Yamanaka, S.; Okushi, H.; Kajimura, K. Study of the effect of hydrogen on transport properties in chemical vapor deposited diamond films by Hall measurements. Appl. Phys. Lett. 1996, 68, 376-378.

(C) 2011 by the authors; licensee MDPI, Basel, Switzerland. This article is an open access article distributed under the terms and conditions of the Creative Commons Attribution license (http://creativecommons.org/licenses/by/3.0/). 